\title{
Multi-channel open tubular traps for headspace sampling, gas chromatographic fraction collection and olfactory assessment of milk volatiles
}

\author{
Yvette Naudéa, ${ }^{\mathrm{a} *}$, Marleen van Aardt ${ }^{\mathrm{b}}$, Egmont Richard Rohwer \\ ${ }^{a}$ Department of Chemistry, ${ }^{\mathrm{b}}$ Department of Food Science, University of Pretoria, Hatfield \\ 0002, South Africa
}

\begin{abstract}
A headspace sampling method is described for concentrating milk volatiles onto a multichannel open tubular silicone rubber trap (MCT) for thermal desorption into a GC-FID. Sections of the chromatographic profile, single peaks or combinations of compounds are recaptured with secondary MCTs during a subsequent run. The recaptured aroma is released in a controlled manner by heating the MCT in a portable heating device. An aroma release window of several minutes allows up to six people the opportunity to sniff each aroma fraction more than once. Olfactory results suggest that a synergistic combination of 2-heptanone and 2-nonanone could be responsible for a pungent cheese, sour milk-like aroma. MCTs containing single components or fractions can be desorbed into a GC-MS for compound identification.
\end{abstract}

Keywords: capillary gas chromatography; sorptive extraction and collection; polydimethyl siloxane; headspace sampling; olfactometry; aroma compounds; milk volatiles.

${ }^{*}$ Corresponding author: Yvette Naudé, Department of Chemistry, Natural Sciences 1, Room 2.19, University of Pretoria, Hatfield, 0002, South Africa, Tel: +27 (0)12 420 2517; Fax: +27 (0)12 4204687 .

E-mail address: yvette.naude@up.ac.za

Naudé, Y., Van Aardt, M., Rohwer, E.R. (2009). Multi-channel open tubular traps for headspace sampling, gas chromatographic fraction collection and olfactory assessment of milk volatiles. Journal of Chromatography A (1216), 2798-2804. doi:10.1016/j.chroma.2008.09.065 


\section{Introduction}

The ultra high temperature (UHT) treatment of milk imparts an undesirable cooked (cabbage, sulphurous, stale, heated, sterile milk) flavour to packaged long life milk [1-4]. Analytical methods that have been used to study the aroma of dairy products are gas chromatography mass spectrometry (GC-MS) and gas chromatography olfactometry (GCO) [5-8]. To identify individual odour active gas chromatographic fractions, GCO is traditionally used: a human record of aroma perception - in real time - of the GC effluent at the olfactometer outlet. GCO can cause nose fatigue and requires utmost concentration. The rapid elution of compounds is problematic in terms of recalling appropriate odour descriptors. Typically one to two trained evaluators perform the sniffing. However, a group of assessors is required for reliable GCO analysis necessitating numerous analyses and multiple gas chromatographs equipped with sniff ports [9]. Instrumental analyses are not always performed on the aroma relevant compounds but also on non odorous compounds that may include hazardous chemicals [10]. Single compounds at a time are evaluated and potential synergistic effects cannot be observed [9]. Since the mechanism governing the combination of individual compounds in the generation of odours is not yet fully understood it is hard to determine how individual compounds of a product relate to the perception of its overall aroma when using traditional instrumental techniques [10]. The discovery of a cluster of olfactory cortex cells in mice responding exclusively to paired odorous molecules but not to either of the single odorous component on its own may explain how mammals and specifically humans sense mixtures of odourants [11]. For example, carnation, a markedly different third scent is perceived when a combination of both eugenol (clove-like aroma) and phenyl ethyl alcohol (rose-like aroma) in a mixture is sniffed [11].

The target compounds chosen for technique evaluation in this study are important thermally derived off-flavour compounds present in UHT milk. Powerful odour active volatiles detected in heated milk include 2-heptanone, 2-nonanone and nonanal, with 2heptanone and 2-nonanone identified as the most intense volatile flavour compounds of UHT milk [12]. Higher concentrations were found of, amongst others, the sulphur compound dimethyl sulphide, the ketones: 2-hexanone, 2-heptanone, 2-nonanone and the aldehydes: 2-methylpropanal, 3-methylbutanal and decanal in UHT milk when compared to concentrations measured in raw and pasteurised milk [3]. Calculated odour activity values (OAV) for dimethyl sulphide, 2,3-butanedione, 2-heptanone, 2-nonanone, 2methylpropanal, 3-methylbutanal, nonanal and decanal show that these compounds may well be important contributors to the off-flavour of UHT milk [3]. The formation of 2,3butanedione is however not only heat-induced but can also point to microbial activity in milk [3].

Extraction techniques for the isolation of volatile components from food matrices include head space solid phase microextraction (HS-SPME), solvent extraction with solventassisted flavour evaporation (SAFE), stir bar sorptive extraction (SBSE), headspace solidphase dynamic extraction (HS-SPDE) and headspace trap technology [4, 13 - 16, 18 21]. Headspace sampling provides solvent-free aroma extracts that are more representative of food aroma when compared to those obtained by solvent extraction. Commercial sorptive extraction techniques, such as SPME, SBSE, SPDE and headspace trap technology, offer efficient concentration and can be used for sampling the headspace [16 - 21]. SPME is a fibre coated with a small sorbent volume of $0.6-0.9 \mu \mathrm{l}[16,18,21]$, SBSE is a stir bar coated with volumes of $25-200 \mu$ polydimethylsiloxane (PDMS) [18], SPDE is a sorptive coating with a sorbent volume of $6 \mu$ on the inside wall of a stainless steel needle of a gas tight syringe [17 - 21], while headspace trap technology makes use 
of a headspace sampler and a built-in trap. The built-in trap is a tube filled with a solid sorbent with a volume of $160 \mu \mathrm{l}$ [21]. In contrast to the commercially available coated fibres, coated capillaries and tubes filled with solid packing material, the headspace traps used in this study are multi-channel open tubular silicone rubber traps (MCTs) prepared inhouse $[22,23,24]$. The PDMS tubing is inserted into a commercial empty desorption tube (Figure 1). The MCT has a considerably larger volume of 635 ul PDMS offering greater sample enrichment. The analytes are concentrated by a purge-and-trap method onto MCTs, followed by thermal desorption of the MCTs into a gas chromatograph with flame ionisation detection (GC-FID). The open tubular structure of the MCTs and low pressure drop make it suitable for the recapturing of aroma fractions, or single aroma compounds, from the GC effluent during a run and also for the off-line release of the recaptured aroma compounds from the MCTs for olfactometric evaluation, as previously demonstrated for the evaluation of beer aroma $[25,26]$. MCTs containing recaptured compounds of unknown identity are desorbed into a GC-MS for compound identification [26].

We report the extraction of odour compounds from packaged long life UHT milk using MCTs for quantitative gas chromatographic analysis, for fractionation and collection of odour compounds for off-line olfactory assessment, for evaluation of combinations of aroma compounds and for GC-MS compound identification. 


\section{Experimental}

\subsection{Chemical standards}

Dimethyl sulphide, 2,3-butanedione, 2-hexanone, 2-heptanone, 2-nonanone, 2methylpropanal, 3-methylbutanal, nonanal and decanal, purity $\geq 98.5 \%$, were purchased from Sigma-Aldrich (Pty) Ltd. (Kempton Park, South Africa).

\subsection{Milk samples}

Three batches of packaged long life UHT milk ( $2 \%$ milk fat) were purchased from a local supermarket (Montana, Gauteng, South Africa) on different days. The milk purchased was the supermarket's own brand. The samples were stored in a refrigerator at $7^{\circ} \mathrm{C}$.

\subsection{Extraction of Aroma Compounds}

\subsubsection{Multi-channel open tubular PDMS trap}

MCTs containing $0.4 \pm 0.02 \mathrm{~g}$ silicone were prepared according to the method described by Ortner and Rohwer [23]. The MCT was designed to fit a commercial thermal desorber system (TDS) available from Gerstel ${ }^{\mathrm{TM}}$. Twenty two channels of silicone elastomer medical grade tubing (0.64 mm OD x $0.3 \mathrm{~mm}$ ID., Sil-Tec, Technical Products, Georgia, USA) were inserted into $17.8 \mathrm{~cm}$ long glass desorption tubes (4 mm ID, $6.00 \mathrm{~mm} \mathrm{OD)} \mathrm{from}$ Gerstel $^{\mathrm{TM}}$ (Chemetrix, Midrand, South Africa). The MCT inside the desorption tube was 55 $\mathrm{mm}$ long (Figure 1).

2.3.2 Sample preparation. A purge-and-trap sampling method developed in-house was used to extract the volatiles from packaged long life UHT milk ( $2 \%$ milk fat) by trapping it on a MCT [24]. The volatiles were isolated from $200 \mathrm{ml}$ milk inside a $500 \mathrm{ml}$ flat bottomed glass flask. The flask was immersed for $35 \mathrm{~min}$ in a water bath $\left(40{ }^{\circ} \mathrm{C}\right)$ to a level slightly above that of the UHT milk in the flask. The sample was purged with $500 \mathrm{ml}$ nitrogen gas (5.0, Afrox, Gauteng, South Africa) at $25 \mathrm{ml} / \mathrm{min}$. The purged volatiles were collected on a $\mathrm{MCT}$ at $45^{\circ} \mathrm{C}$ to minimise the condensation of water from the sample onto the MCT. A second sorption tube was connected to the primary MCT for the determination of breakthrough of the volatiles from the primary MCT. A sorption tube filled with $2 / 3$ Tenax TA (60/80) / 1/3 Carboxen 1003 (40/60) (Gerstel ${ }^{\mathrm{TM}}$, Chemetrix, Midrand, South Africa) and a MCT were both evaluated for suitability as back-up traps for the primary MCT. After extraction of the milk sample, $0.5 \mathrm{~g}$ of silica gel (Saarchem uniLABß, particle size $1-3$ $\mathrm{mm}$, Merck Chemicals (Pty) Ltd, Gauteng, South Africa) was added, as a drying agent, to the sorption tube containing the MCT. After 60 min the silica gel was removed.

[Figure 1]

\subsection{GC-FID with thermal desorption and cryo inlet system}

The volatiles were thermally desorbed from the MCT using a TDS from Gerstel ${ }^{\mathrm{TM}}$ installed on an Agilent 6890 GC-FID (Chemetrix, Midrand, South Africa). Splitless desorption was from $30{ }^{\circ} \mathrm{C}(3 \mathrm{~min})$ at $60{ }^{\circ} \mathrm{C} / \mathrm{min}$ to $210{ }^{\circ} \mathrm{C}(10 \mathrm{~min})$. The desorption flow rate was 50 $\mathrm{ml} / \mathrm{min}$ (hydrogen gas, Afrox, Gauteng, South Africa) at $47 \mathrm{kPa}$. The TDS transfer line temperature was $250{ }^{\circ} \mathrm{C}$. The volatiles were cryogenically focused using liquid nitrogen at $-100{ }^{\circ} \mathrm{C}$ on a cooled injection system (CIS). The CIS liner contained silicone rubber to improve retention of the extremely volatile dimethyl sulphide. After desorption of the analytes from the MCT, the CIS was heated to $200^{\circ} \mathrm{C}$ at $5{ }^{\circ} \mathrm{C} / \mathrm{s}$ and the volatiles were analysed by GC-FID $\left(310^{\circ} \mathrm{C}\right)$. The GC oven temperature programme was $-50{ }^{\circ} \mathrm{C}(3 \mathrm{~min})$ 
at $10{ }^{\circ} \mathrm{C} / \mathrm{min}$ to $120^{\circ} \mathrm{C}(10 \mathrm{~min}), 10^{\circ} \mathrm{C} / \mathrm{min}$ to $220^{\circ} \mathrm{C}$. Hydrogen carrier gas velocity was $33 \mathrm{~cm} / \mathrm{s}(2.3 \mathrm{ml} / \mathrm{min})$ and the column head pressure was $23 \mathrm{kPa}$ in the constant pressure mode. The GC column was a Zebron ZB-1 $30 \mathrm{~m}$ x $320 \mu \mathrm{m}$ ID x $1 \mu \mathrm{m}$ film thickness (Phenomenex, Separations, Randburg, South Africa).

\subsection{Quantification}

A standard stock solution was prepared in methanol (Saarchem UniVAR, Merck Chemicals (Pty) Ltd., Kempton Park, South Africa) containing dimethyl sulphide, 2,3butanedione, 2-hexanone, 2-heptanone, 2-nonanone, 2-methylpropanal, 3-methylbutanal, nonanal and decanal to give a concentration of $1 \mu \mathrm{g} / \mu \mathrm{l}$. Standard solution was added to $200 \mathrm{ml}$ long life packaged UHT milk ( $2 \%$ milk fat) to give final concentrations of $0.4,0.8$, $4,8,16,40,70,85 \mu \mathrm{g} / 200 \mathrm{ml}$. Chilled long life UHT milk from the refrigerator was spiked, mixed on a vortex mixer and equilibrated for $20 \mathrm{~min}$ in the refrigerator. The spiked samples were extracted as described previously. Calibration curves (matrix-assisted standard addition) for the compounds were constructed and linear regression analysis was used.

\subsection{Capturing of single compounds and fractions by gas chromatography fraction collection (GCFC)}

A chromatographic profile of the packaged long life UHT milk is first obtained using the conditions described previously. Integration results of peak start time and peak end time of the chromatogram of the UHT milk were then used to establish the compound/fraction recapturing event times. In a subsequent run, various sections of the GC-effluent were recaptured, with secondary MCTs on a carefully timed basis. Manual collection commenced $30 \mathrm{~s}$ before peak elution and ended $10 \mathrm{~s}$ after elution had completed (Table 1). For GCFC the instrumental conditions were as previously described, the only difference was the modification of the detector parameters. The electrometer was switched off. The detector top assembly and the collector were removed by loosening the knurled brass of the detector assembly and by lifting the collector out. Single peaks or fractions were collected at the end of the GC column by placing a secondary MCT on the FID flame tip and by supporting the MCT in this position by hand (Figure 2). During collection the FID and flame gases (hydrogen and air) were switched off, the make-up gas (helium) plus carrier gas (hydrogen) flow totalled $50 \mathrm{ml} / \mathrm{min}$ and the detector temperature was at $100^{\circ} \mathrm{C}$. After fractions or single compounds were recaptured the MCT was capped and stored for olfactory evaluation and for GC-MS identification.

Table 1

[Figure 2]

\subsection{Olfactory evaluation of captured fractions and single compounds on secondary MCTs}

The aroma was released in a controlled manner by heating the secondary MCT containing the recaptured component/s from the GC-effluent in a portable heating device with a flow of nitrogen gas at a desorption flow rate of $20 \mathrm{ml} / \mathrm{min}$. The MCTs were inserted in the cavity in the portable heating device. The compounds were released from the secondary MCTs at GC column elution temperature for the single compounds. As the aroma eluted from the MCT it was sniffed by a team consisting of six experienced non smoking evaluators (five female, one male). All six of the evaluators participated as a group during the same assessment session. For the evaluation of combinations of compounds the 
fractions were released at $130{ }^{\circ} \mathrm{C}$ and at $160{ }^{\circ} \mathrm{C}$ and the aroma was evaluated by a panel of three persons.

\subsection{Identification of volatile compounds by GC-MS}

The recaptured analytes (obtained with GCFC) were desorbed using a Gerstel TDS installed on a Hewlett Packard (HP) GC 1530A coupled to a HP 5973 mass selective detector (MSD) (Chemetrix, Johannesburg, South Africa). The MCTs were desorbed from $30{ }^{\circ} \mathrm{C}(3 \mathrm{~min})$ at $60^{\circ} \mathrm{C} / \mathrm{min}$ to $210^{\circ} \mathrm{C}(10 \mathrm{~min})$, the desorption flow was $60 \mathrm{ml} / \mathrm{min}$ at 65 $\mathrm{kPa}$ (Helium, Ultra High Purity, Afrox, Johannesburg) in the splitless desorption mode allowing for total transfer of analytes to the cold trap. The TDS transfer line temperature was $250{ }^{\circ} \mathrm{C}$. The desorbed analytes were cryogenically focused on a CIS at $-100{ }^{\circ} \mathrm{C}$ using liquid nitrogen. The inlet liner contained silicone rubber to improve the retention of the volatile analytes. After desorption, a splitless injection (purge on at $30 \mathrm{~min}$, purge flow $30 \mathrm{ml} / \mathrm{min}$ ) was performed by heating the $\mathrm{CIS}$ from $-100{ }^{\circ} \mathrm{C}$ at $5^{\circ} \mathrm{C} / \mathrm{s}$ to $200{ }^{\circ} \mathrm{C}$ for $10 \mathrm{~min}$. The GC column was a Zebron, ZB1 $30 \mathrm{~m} \times 250 \mu \mathrm{m}$ ID $\times 0.25 \mu \mathrm{m}$ film thickness (Phenomenex, Separations, Randburg, South Africa), the velocity of the carrier gas (helium) was $42 \mathrm{~cm} / \mathrm{s}(1.3 \mathrm{ml} / \mathrm{min})$ and the column head pressure was $65 \mathrm{kPa}$ in the constant pressure mode. The GC oven temperature programme was $-50^{\circ} \mathrm{C}(3 \mathrm{~min})$ at 10 ${ }^{\circ} \mathrm{C} / \mathrm{min}$ to $220^{\circ} \mathrm{C}(1 \mathrm{~min})$. The GC run time was $31 \mathrm{~min}$. The GC-MS transfer line was at $250^{\circ} \mathrm{C}$, the mass scan range was 35-300 atomic mass units in full scan mode, the source $(\mathrm{EI}+)$ temperature $230{ }^{\circ} \mathrm{C}$, the MS quadrupole temperature $150{ }^{\circ} \mathrm{C}$, the ionisation energy $70 \mathrm{eV}$ and the electron multiplier (EM) $1700 \mathrm{~V}$. The identities of the volatiles were confirmed by comparison of the retention times of the analytes in the sample to the retention times of the standards, by mass spectra comparison of the standards to that of the analytes and to the mass spectra found in a commercial library (Wiley). Matches of the mass spectra of the components to that of the library were $\geq 90 \%$.

\section{Results and discussion}

\subsection{Extraction of aroma compounds and GC-FID with thermal desorption and CIS}

In order to collect all of the target analytes $\left(\mathrm{C}_{2}-\mathrm{C}_{10}\right)$ from the UHT milk within a single extraction step a second sorption tube containing 2/3 Tenax TA (60/80) and 1/3 Carboxen 1003 (40/60) was connected as a backup trap to the primary MCT. When the MCT was desorbed for analysis of the $\mathrm{C}_{6}-\mathrm{C}_{10}$ fraction (2-hexanone, 2-heptanone, 2-nonanone, nonanal, decanal) we found, contrary to expectation, that the $C_{2}-C_{5}$ volatile fraction (dimethyl sulphide, 2-methylpropanal, 2,3-butanedione, 3-methylbutanal) was present on the primary MCT. The Tenax/Carboxen tube was then desorbed to determine if breakthrough occurred from the primary MCT onto the second backup trap. However, desorption of the Tenax/Carboxen tube was problematic due to the dense packing of the sorption material which caused a high inlet pressure and gas flow shut down, even at very low desorption flow rates. Hence, the use of a Tenax/Carboxen sorption tube as a backup trap for the primary MCT was discontinued. Instead, a second MCT was connected as a backup trap to the primary MCT to determine the level of breakthrough from the first MCT onto the second MCT. Due to the open tubular structure of the MCT, problems with inlet pressure and gas flow were not experienced. For the $\mathrm{C}_{2}-\mathrm{C}_{5}$ volatile fraction (dimethyl sulphide, 2-methylpropanal, 2,3-butanedione, 3-methylbutanal) breakthrough levels were at $47-51 \%$ and for the $\mathrm{C}_{6}-\mathrm{C}_{10}$ fraction (2-hexanone, 2-heptanone, 2-nonanone, nonanal, decanal) breakthrough was $0-10 \%$. 
The inlet liner contained a $7 \mathrm{~cm}$ length of silicone rubber tubing $( \pm 10 \mathrm{mg})$ which dramatically improved the retention and thus focusing of the extremely volatile dimethyl sulphide. Pronounced peak broadening occurred when there was no silicone rubber in the inlet liner, indicating breakthrough from the CIS during desorption of the MCT. Peak broadening of dimethyl sulphide was still observed during the TDS desorption cycle when the GC oven was at ambient temperature. Therefore the oven was cryogenically cooled to $-50^{\circ} \mathrm{C}$ using liquid nitrogen to obtain narrower GC peaks for dimethyl sulphide. Some residual moisture was collected onto the MCT during extraction of the UHT milk. The moisture caused FID signal instability, shifting the retention times of the early eluting compounds (dimethyl sulphide, 2-methylpropanal, 2,3-butanedione, 3-methylbutanal) when using a GC column with a $0.25 \mu \mathrm{m}$ film thickness. To reduce the moisture and to improve retention time repeatability, silica gel was added to the TDS sorption tube containing the MCT. A drying period of one hour was sufficient to dry the MCT. However, when using silica gel a 50\% loss from the MCT occurred for dimethyl sulphide and 2methylpropanal. A thicker film $(1 \mu \mathrm{m}) \mathrm{GC}$ column was therefore rather used in this particular application. The thicker film column was less sensitive to any residual moisture which improved FID signal stability and also retention time repeatability of the early eluting compounds.

\subsection{Quantification of the aroma compounds}

Table 2 shows the results of the linear regression analysis of the calibration $(n=8)$ based on the method of standard addition [3]. 2,3-Butanedione was excluded from the quantification results because the purity of the purchased reference standard was compromised. The concentrations of the aroma compounds present in a sample $(n=1)$ from the second batch and a sample $(n=1)$ from the third batch of packaged long life UHT milk ( $2 \%$ milk fat) used for fraction collection and for the off-line release of the captured aromas are given in Table 3 . The concentrations were calculated from the regression equations in Table 2. The first batch of UHT milk samples was used for technique development.

Table 2

Table 3

\subsection{Capturing of single compounds and fractions by GCFC}

Single compounds or combinations of compounds were collected on secondary MCTs. Figure 3 shows the comparison of the primary chromatogram of a primary MCT containing compounds from UHT milk spiked at $195-245 \mu \mathrm{g} / \mathrm{l}$, and the secondary chromatograms of secondary MCTs containing compounds that were recaptured from the GC effluent after desorption of primary MCTs containing spiked $(195-245 \mu \mathrm{g} / \mathrm{l})$ and unspiked $(1-44 \mu \mathrm{g} / \mathrm{l})$ compounds from UHT milk. The nine compounds were selectively recaptured from the GC effluent so that each secondary MCT contained only the nine target compounds, excluding the remainder of the chromatographic profile. A clean chromatographic secondary profile is thus obtained for the secondary MCTs in contrast to the chromatogram of the primary MCT. The efficiency of recapturing compounds onto secondary MCTs at the GC effluent by this manual method and the re-injection of the fractions were $40-70 \%$ (Figure 3 ). This fraction collection method required at least five seconds for the manual exchange of the secondary MCTs. Figure 4 shows the secondary chromatograms of compounds that are $23 \mathrm{~s}$ apart. The compounds were recaptured individually with 2-nonanone recaptured onto MCT 1 and nonanal recaptured onto MCT 2. Since only a small fraction of the large number of volatiles occurring in a particular matrix contributes to the aroma, a distinction must be made between odour active compounds and the whole range of volatiles present 
[9]. Thus, for the olfactory assessment, the target compounds were captured exclusively so that each MCT contained a single compound excluding the compounds that make up the remainder of the chromatographic profile.

Figure 3

Figure 4

\subsection{GC-MS of a compound recaptured by GCFC}

To confirm that dimethyl sulphide was indeed concentrated onto the primary MCT during extraction the peak was recaptured at the end of the GC effluent onto a secondary MCT. The secondary MCT was desorbed into the GC-MS. The retention time and the mass spectrum of the captured peak matched that of the chemical standard and the spectra of the Wiley library. Recapturing of odour active compounds from the GC effluent onto secondary MCTs for analysis by GC-MS can be especially useful when dealing with compounds of unknown identity.

\subsection{Release of recaptured aroma compounds and the aroma of the overall milk profile from the MCTs for off-line olfactory assessment}

Nine odour active compounds (sulphide, aldehydes and ketones) were selected for evaluation and comparison to the aroma of the overall milk profile. Due to the UHT treatment a cooked flavour is imparted when the levels of the compounds in packaged long life UHT milk exceed the levels typically found in freshly pasteurised milk. The low pressure drop of the open tubular channels of the MCT allows most of the effluent of the FID to pass through the trap without special sealing arrangement that would otherwise complicate the GCFC procedure. The advantage of a low pressure drop is not offered by conventional packed traps. After GCFC onto secondary MCTs, the MCTs were desorbed with a flow of nitrogen gas in a portable heating device which resulted in the controlled release of aroma from single compounds or fractions. The aroma from primary MCTs containing the overall milk profile was also released for comparison to that of the single compounds and fractions. An aroma release window of about three minutes was achieved, allowing up to six people the opportunity to each sniff the aroma more than once during the same release session. This gave ample opportunity for recalling odour descriptors unlike the case for GCO. Quick decisions can impair judgment and attentiveness decreases during a long assessment session. An advantage of GCFC onto MCTs for off-line aroma release is that the olfactory assessment could be terminated and resumed at convenience when the evaluators indicated nose fatigue.

Results of the olfactory assessment of the individual compounds (spike levels of $195-245$ $\mathrm{ug} / \mathrm{l}$ in UHT milk) are given in Table 4. The aroma descriptors reported by the evaluators for each of the individual compounds generally matched the descriptors reported in the literature $[2,5,27]$. A fairly neutral background was described for the recaptured single compounds and the overall milk profile captured from the unspiked UHT milk (Table 4). However, when the overall aroma from the spiked UHT milk (spike level of $79-85 \mu \mathrm{g} / \mathrm{l}$ ) collected on a single primary MCT was released, the aroma matched the descriptors for the single compounds up to and including 2-hexanone. Thereafter, the aroma observed deviated markedly from the descriptors for the individual compounds. Instead of observing the expected aroma of "soapy" (2-heptanone) and "fruity" (2-nonanone), a sharp, sour milk-like, sweaty aroma was noted. This unexpected and entirely new aroma suggested possible synergistic effects between the compounds, or the presence of other compounds 
in the chromatographic profile that are not in the target list of compounds. The unpleasant aroma was absent when the single compounds recaptured during GCFC were sniffed, and when the overall aroma profile of the unspiked milk was sniffed (Table 4).

\section{Table 4}

\subsection{Evaluation of combinations of compounds to assess synergistic effects}

Combinations of the volatiles were collected onto secondary MCTs during GCFC to determine which compounds were responsible for the modification of the expected fruity, soapy and sweet aroma into the unexpected and wholly new aroma described as pungent, sour milk-like and sweaty. A malty aroma dominated when a combination of the aldehyde 3-methylbutanal (malty, sweet), and the ketone 2-hexanone ("feed") was sniffed (compounds 4 and 5) (Table 4). A milky-sweet, condensed milk aroma was described for the combination of the ketones, 2-Hexanone ("feed") and 2-Heptanone (soapy, fruity, floral) (compounds 5 and 6 ). A pungent, feta cheese, blue cheese, sweaty, sour, fatty aroma was observed when a combination of the ketones, 2-heptanone (soapy, fruity, floral) and 2-nonanone (fruity, sweet), was sniffed (compounds 6 and 7) (Table 4). A low intensity cheesy, sweaty, sour aroma was noted when a combination of the ketones, 2hexanone ("feed") and 2-nonanone (fruity, sweet), was sniffed (compounds 5 and 7) (Table 4).

The results from the olfactory assessment show that the aroma of the individual ketones is distinctly different to the aroma of mixtures of ketones. The combination of 2-nonanone with either 2-heptanone or 2-hexanone, gave a cheesy odour, whilst the combination of 2hexanone and 2-heptanone did not give a cheesy aroma. The combination of 2heptanone and 2-nonanone was responsible for the pungent cheese, sour milk-like aroma observed when the overall milk aroma was sniffed. This result seems consistent with the findings of both Vazquez-Landaverde et al. (2005) who reported that the odour activity values for 2-heptanone and 2-nonanone suggest that these compounds could be very important contributors to the aroma of heated milk, and of Moio et al. who applied CharmAnalysis ${ }^{\circledR}$ to identify 2-heptanone and 2-nonanone as the two most intense flavour compounds likely to be the main odourants of UHT milk $[3,12]$. 


\section{Conclusions}

The headspace sampling technique developed in this study allows for the quantitative analysis of aroma compounds from long life packaged UHT milk ( $2 \%$ milk fat) by concentrating the compounds onto a MCT designed to fit a commercial GC desorber. The GCFC technique can recapture single compounds, sections, or the actual aroma profile (excluding unwanted compounds) of milk for off-line olfactory evaluation by a number of people participating in the same assessment session. The slow release of aroma allows for sufficient time to recall odour descriptors. Combinations of individual compounds can be recaptured to study potential synergistic effects. A mixture of 2-heptanone and 2nonanone was found to be responsible for a pungent cheese, sour milk-like aroma descriptors not observed for the single compounds. MCTs containing single components or fractions can be desorbed into a GC-MS for compound identification.

The described instrumentation allows comparison of olfactometric perception of a concentrated overall aroma against that of gas chromatographically separated single compounds, a feature not offered by traditional GCO. In this particular study, the contrast between descriptors of the overall aroma and the single compounds in the low volatility aroma region could be reconciled by a trial-and-error search for a simple combination of single compounds that matched a descriptor for the whole aroma, not registered for any of the single peaks alone.

Note added in proof: It was only learnt after completion of the study that 2-heptanone and 2-nonanone are the ketones central to the characteristic blue cheese aroma of bluemould ripened cheese, and that these two compounds are indeed used as additives to impart a cheese aroma [28 - 30].

\section{Acknowledgements}

The authors thank Sasol for financial support, Mr Musa Lonwabo Kwetana for assistance in sample extractions, the olfactory panel: Dr Marleen van Aardt, Prof Elna Buys, Dr Henriette de Kock, Ms Marise Kinnear and Mr Alex Zabbia of the Department of Food Science, University of Pretoria, Mrs Margaux Lim Ah Tock and Dr Fanie van der Walt for the portable heating device. 


\section{References}

[1] G. Contarini, M. Povolo, R. Leardi, P.M. Toppino, J. Agric. Food Chem. 45 (1997) 3171.

[2] H.E. Nursten, Int J of Dairy Technol. 50 (2) (1997) 48.

[3] P.A. Vazquez-Landaverde, G. Velazquez, J.A. Torres, M.C. Qian, J. Dairy Sci. 88 (2005) 3764.

[4] P.A. Vazquez-Landaverde, J.A. Torres, M.C. Qian, J. Agric. Food Chem. 54 (2006) 9184.

[5] J.E. Friedrich, T.E. Acree, Int. Dairy J. 8 (3) (1998) 235.

[6] J.G. Bendall, J. Agric. Food Chem. 49 (2001) 4825.

[7] S.S. Mahajan, L. Goddik, M.C Qian, J. Diary Sci. 87 (2004) 4057.

[8] M. van Aardt, S.E. Duncan, J.E. Marcy, T.E. Long, S.F. O’ Keefe, S.R. NielsenSims, J. Dairy Sci. 88 (2005) 881.

[9] S. M. van Ruth, Biomol. Eng. 17 (2001) 121.

[10] S. Ampuero, J.O. Bosset, Sensors and Actuators B 94 (2003) 1.

[11] Z. Zou, L. B. Buck, Science 311 (2006) 1477.

[12] L. Moio, P. Etievant, D. Langlois, J. Dekimpe, F. Addeo, J. Dairy Res. 61 (1994) 385.

[13] M. Fabre, V. Aubry, E. Guichard, J. Agric. Food Chem. 50 (2002) 1497.

[14] A. Buettner, Flavour Fragr. J. 22 (2007) 465.

[15] M. van Aardt, E.R. Rohwer, Y. Naudé, E.M. Buys, H.L. de Kock, in preparation for submission to J. Dairy Sci. 2008.

[16] C. Bicchi, C. Cordero, C. Iori, P. Rubiolo, J. High Resol. Chromatogr. 23 (9) (2000) 539.

[17] D.W. Lachenmeier, L. Kroener, F. Musshoff, B. Madea, Rapid Commun. Mass Spectrom. 17 (2003) 472.

[18] C. Bicchi, C. Cordero, E. Liberto, P. Rubiolo, B. Sgorbini, J. Chromatogr A 1024 (2004) 217.

[19] K. Ridgway, S.P.D. Lalljie, R.M. Smith, J. Chromatogr A 1124 (2006) 181.

[20] K. Ridgway, S.P.D. Lalljie, R.M. Smith, J. Chromatogr A 1174 (2007) 20.

[21] K. Schulz, J. Dreßler, E. Sohnius, D.W. Lachenmeier, J. Chromatogr A 1145 (2007) 204.

[22] E.R. Rohwer, M.J. Lim Ah Tock, Y. Naudé, SA provisional patent application ZA 2006/07538, 2006.

[23] E.K. Ortner, E.R. Rohwer, J. High Resolut. Chromatogr. 19 (1996) 339.

[24] D. Sivakumar, Y. Naudé, E. Rohwer, L. Korsten, Sci Food Agric. 88 (2008) 1074.

[25] M. Lim Ah Tock, E.R. Rohwer, Y. Naudé, Proceedings of the $5^{\text {th }}$ Analitika 2006 Conference, KwaMaritane, Pilanesberg, South Africa, 2006, p.23.

[26] Y. Naudé, M. van Aardt, E.R. Rohwer, Abstract book of the $32^{\text {nd }}$ International symposium on capillary chromatography and $5^{\text {th }}$ GCxGC symposium, Riva del Garda, Italy, 2008, p.432.

[27] M. Rychlik, P. Schieberle, W. Gosch, Compilation of odor thresholds, odor qualities and retention indices of key food odorants, Deutsche Forschungsanstalt für Lebensmittelchemie and Institut für Lebensmittelchemie der Technischen Universität München, Garching, Germany, 1998.

[28] S. Patton, J. Dairy Sci. 33 (1950) 680.

[29] M. Qian, C. Nelson, S. Bloomer, JAOCS. 79 (2002) 663.

[30] L. Moio, P. Piombino, F. Addeo, J. Dairy Res. 67 (2000) 273. 
Table 1

GCFC event times - peak capturing time table

Compound Collection start time (min) Collection end time (min)

1. Dimethyl Sulphide

12.28

13.00

13.70

15.20

18.30

20.70

28.20

29.08

33.60
12.91

13.62

14.50

15.84

19.00

21.50

28.92

29.80

34.35

\section{Table 2}

Regression equations for UHT milk aroma compounds spiked into long life packaged UHT milk (2\% milk fat)

\begin{tabular}{llll}
\hline Compound & Regression equation & $\mathrm{R}^{2}$ & $\mathrm{LOQ}^{2}(\mu \mathrm{g} / \mathrm{l})$ \\
\hline 1. Dimethyl Sulphide & $y=2.67 x$ & 0.994 & 3.745 \\
2. 2-Methylpropanal & $y=3.218 x$ & 0.998 & 3.107 \\
3. 2,3-Butanedione & - & - & - \\
4. 3-Methylbutanal & $y=11.56 x$ & 0.997 & 0.855 \\
5. 2-Hexanone & $y=17.462 x$ & 0.988 & 0.574 \\
6. 2-Heptanone & $y=3.213$ & 0.999 & 0.620 \\
7. 2-Nonanone & $y=2.849 x$ & 0.995 & 3.644 \\
8. Nonanal & $y=2.517 x$ & 0.997 & 3.961 \\
9. Decanal & $y=0.803 x$ & 0.996 & 12.844 \\
\hline
\end{tabular}

${ }^{1} y=$ Peak Area of compound, $x=$ concentration of the compound $\mu \mathrm{g} / \mathrm{l}$.

${ }^{2}$ Limit of quantification (LOQ) calculated as the concentration that gives a signal-to-noise $(\mathrm{S} / \mathrm{N})$ ratio of 10 .

Table 3

Concentrations of the aroma compounds in UHT milk ( $2 \%$ milk fat) used for GCFC and olfactory assessment

Compound $\quad$ UHT batch $2(\mu \mathrm{g} / \mathrm{l}) \quad$ UHT batch $3(\mu \mathrm{g} / \mathrm{l})$

1. Dimethyl Sulphide

2. 2-Methylpropanal

3. 2,3-Butanedione

4. 3-Methylbutanal

5. 2-Hexanone

6. 2-Heptanone

7. 2-Nonanone

8. Nonanal

9. Decanal
6.500

3.296

$-$

1.577

1.226

28.420

29.423

37.927

43.875
15.016

$<3.107$

$-$

1.108

1.205

37.153

36.294

37.727

13.501 
Table 4

Olfactory assessment of recaptured single compounds on individual secondary MCTs ${ }^{1}$, the overall milk aroma on primary $\mathrm{MCTs}^{2}$ and combinations of compounds recaptured onto secondary $\mathrm{MCTs}^{3}$

\begin{tabular}{|c|c|c|c|}
\hline \multirow[t]{2}{*}{ Compound } & \multirow{2}{*}{$\begin{array}{l}\text { Aroma release } \\
\text { temperature } \\
{ }^{\circ} \mathrm{C}\end{array}$} & \multicolumn{2}{|c|}{${ }^{1}$ Aroma description for single compounds ( $\left.n=6\right)$} \\
\hline & & $\begin{array}{l}\text { Spiked UHT milk } \\
195-245 \mu \mathrm{g} / \mathrm{l}\end{array}$ & $\begin{array}{l}\text { Unspiked ÜHT } \\
\text { milk } 1-44 \mu \mathrm{g} / \mathrm{l}\end{array}$ \\
\hline 1. Dimethyl Sulphide & 21 & Sulphurous, rotten egg +++ & - \\
\hline 2. 2-Methylpropanal & 50 & Malty, chemical sweet +++ & - \\
\hline 3. 2,3-Butanedione & 60 & Butter +++ & - \\
\hline 4. 3-Methylbutanal & 73 & Malty, chemical sweet +++ & Chemical sweet + \\
\hline 5. 2-Hexanone & 103 & Feed, hay, field, veld grass ++ & - \\
\hline 6. 2-Heptanone & 128 & Fragrant soap, fruity, floral ++ & Fragrant soap + \\
\hline 7. 2-Nonanone & 178 & Fruity, sweet +++ & Fruity, sweet ++ \\
\hline 8. Nonanal & 185 & Biscuit, cotton candy, caramel ++ & - \\
\hline 9. Decanal & 194 & Dusty, musty, rubber ++ & Dusty, rubber + \\
\hline
\end{tabular}

\begin{tabular}{|c|c|c|c|}
\hline & Aroma release & ${ }^{2}$ Aroma description for the & illk aroma $(n=3)$ \\
\hline & $\begin{array}{l}\text { Temperature } \\
{ }^{\circ} \mathrm{C}\end{array}$ & $\begin{array}{l}\text { Spiked UHT milk } \\
195-245 \mu \mathrm{g} / \mathrm{l}\end{array}$ & $\begin{array}{l}\text { Unspiked UHT } \\
\text { milk } 1-44 \mathrm{uq} / \mathrm{l}\end{array}$ \\
\hline & $24-40$ & $\begin{array}{l}\text { Rotten egg }+ \text {, butter }+++ \text {, } \\
\text { sweet }+, \text { malty }+++\end{array}$ & - \\
\hline & $60-120$ & $\begin{array}{l}\text { Malty+, feed, pungent, } \\
\text { sour milk, sweaty+++ }\end{array}$ & Chemical sweet + \\
\hline & $120-185$ & Sour milk, burnt milk ++ & $\begin{array}{l}\text { Fragrant soap, } \\
\text { floral + }\end{array}$ \\
\hline $\begin{array}{l}\text { Compound } \\
\text { combinations }\end{array}$ & $\begin{array}{l}\text { Aroma release } \\
\text { temperature }{ }^{\circ} \mathrm{C}\end{array}$ & $\begin{array}{l}{ }^{3} \text { Aroma description for cor } \\
\text { Spiked UHT milk } 195-24\end{array}$ & s of compound $(n=3)$ \\
\hline $\begin{array}{l}\text { 4. 3-Methylbutanal } \\
\text { 5. 2-Hexanone }\end{array}$ & 130 & Malty+++, sweet+ & \\
\hline $\begin{array}{l}\text { 5. 2-Hexanone } \\
\text { 6. 2-Heptanone }\end{array}$ & 160 & Milky-sweet, condensed $\mathrm{n}$ & \\
\hline $\begin{array}{l}\text { 6. 2-Heptanone } \\
\text { 7. 2-Nonanone }\end{array}$ & 160 & Feta cheese, blue cheese & sour, fatty +++ \\
\hline $\begin{array}{l}\text { 5. 2-Hexanone } \\
\text { 7. 2-Nonanone }\end{array}$ & 160 & Cheesy, sweaty, sour + & \\
\hline
\end{tabular}

+ Intensity indicator. ${ }^{1}$ Olfactory evaluation of packaged long life UHT milk (2\% milk fat): spiked and unspiked. For each sample nine secondary MCTs were each desorbed in the portable sniffing device at specific temperatures with a flow of nitrogen gas of $20 \mathrm{ml} / \mathrm{min}$. ${ }^{2}$ Olfactory evaluation of the extracted overall milk aroma (primary MCTs, not GCFC) of long life packaged UHT milk ( $2 \%$ milk fat): spiked and unspiked. The MCTs were desorbed in the portable sniffing device from 24 ${ }^{\circ} \mathrm{C}$ to $185{ }^{\circ} \mathrm{C}$ over a period of 60 minutes with a flow of nitrogen gas of $20 \mathrm{ml} / \mathrm{min}$. ${ }^{3}$ Olfactory evaluation of long life packaged UHT milk ( $2 \%$ milk fat): spiked. For each sample four secondary MCTs were each desorbed in the portable sniffing device with a flow of nitrogen gas of $20 \mathrm{ml} / \mathrm{min}$. 


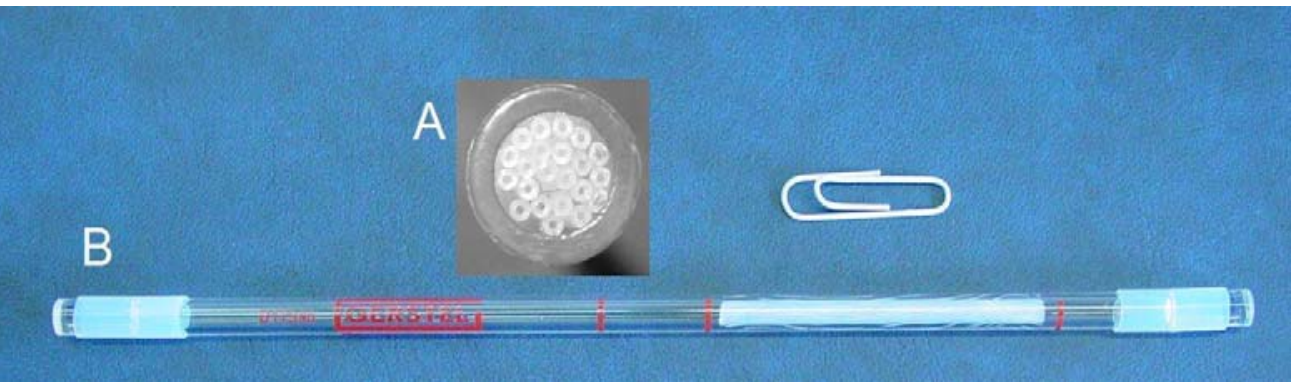

Fig. 1. ${ }^{A}$ Cross section of a MCT. ${ }^{B}$ MCT fits a commercial glass desorption tube.

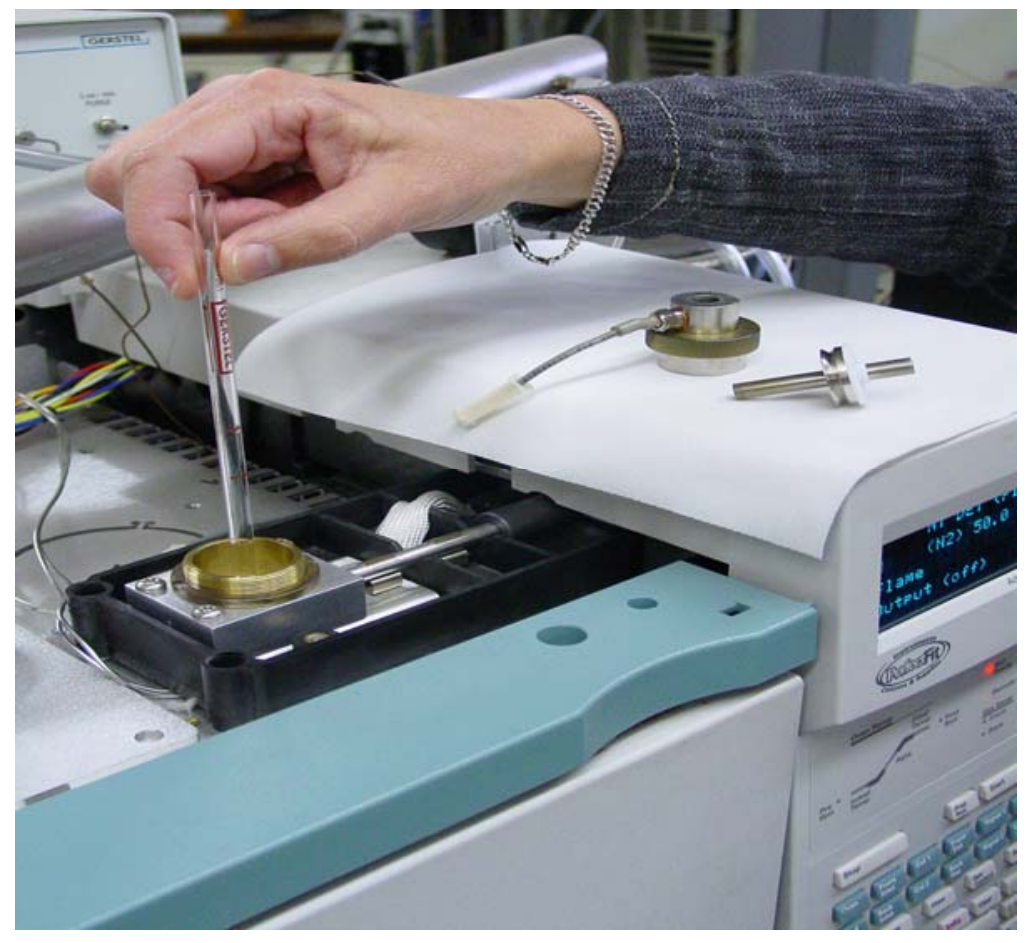

Fig. 2. Removed detector top assembly and collector. MCT placed on GC-FID flame tip to recapture single peaks or various fractions [25]. Helium was used as the make-up gas. 


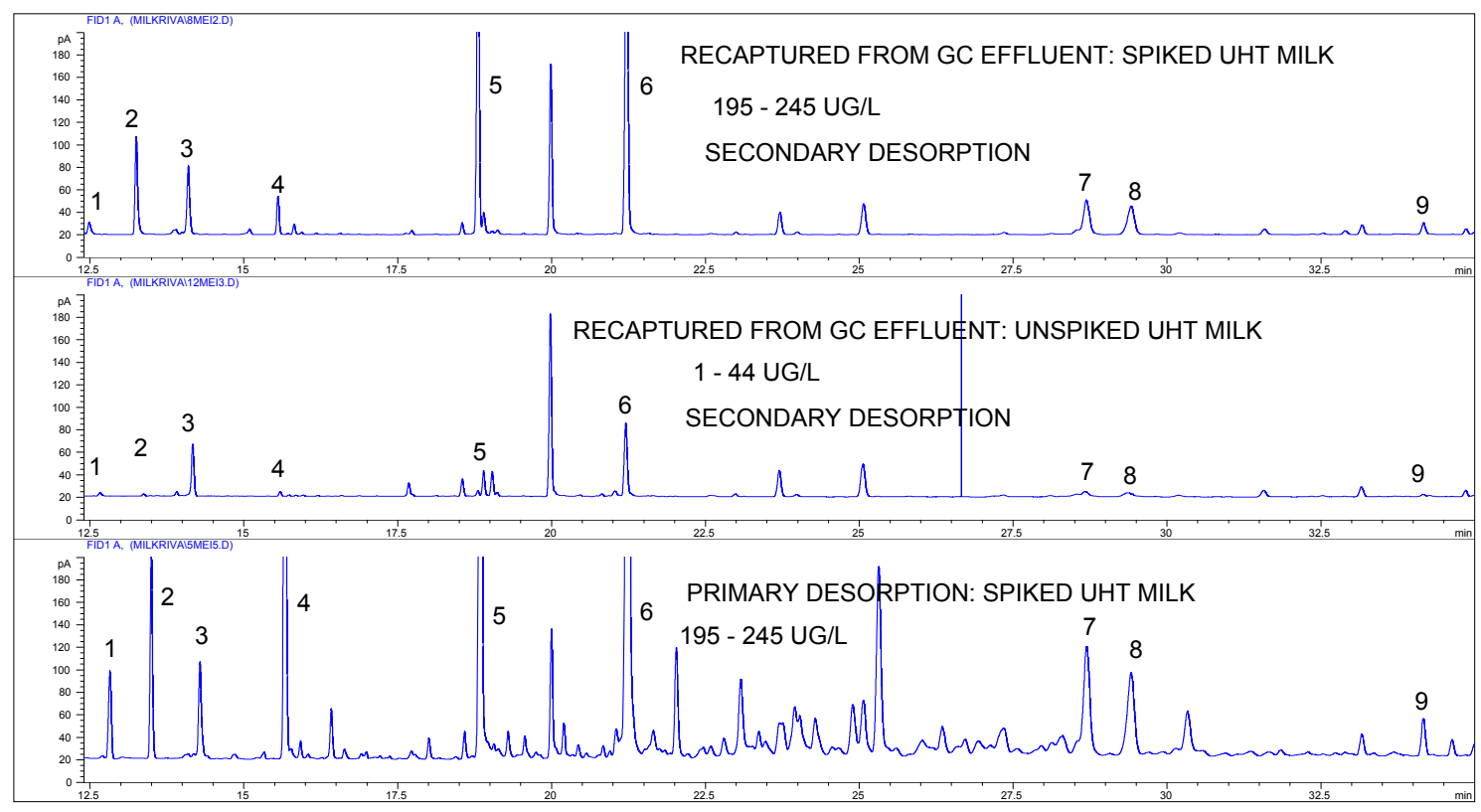

Fig. 3. Trapping and re-injection efficiency: comparison of the desorption of the secondary MCTs containing the recaptured compounds (single compounds were recaptured from the GC effluent all on the same secondary MCT) of spiked (195 - $245 \mu \mathrm{g} / \mathrm{l})$ and unspiked $(1-44 \mu \mathrm{g} / \mathrm{l})$ UHT milk ( $2 \%$ milk fat) to the primary chromatogram of UHT milk (2\% milk fat) spiked at $195-245 \mu \mathrm{g} / \mathrm{l}$. For detail see text; for compound identification see Table 1.

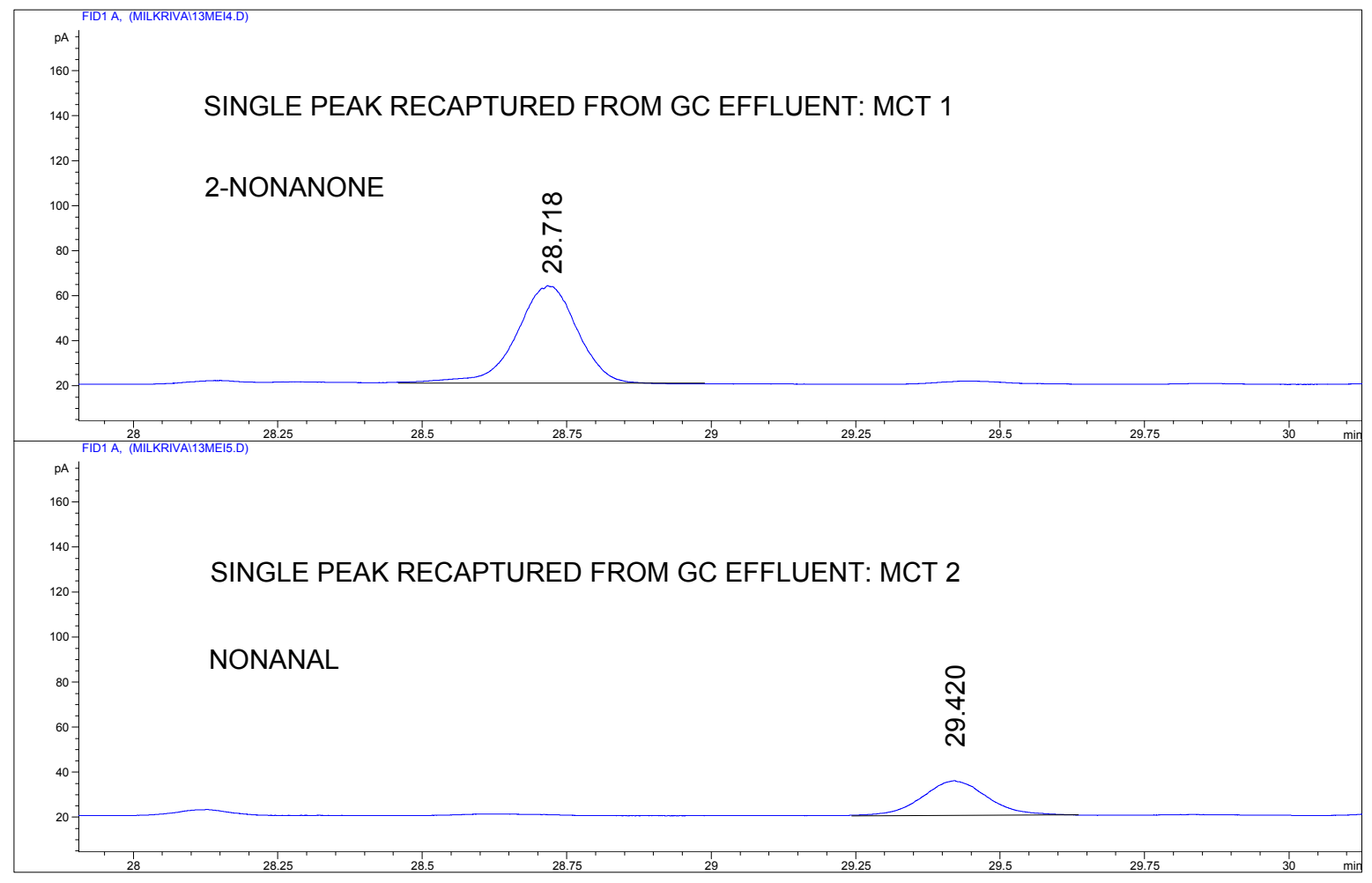

Fig. 4. Secondary chromatograms of packaged long life UHT milk spiked at $195-245$ $\mu \mathrm{g} / \mathrm{l}$. The single compounds (2-nonanone and nonanal) were separately collected on two different MCTs. The peaks captured were $23 \mathrm{~s}$ apart. For detail see text. 
